\title{
Hair keratin KRT81 is expressed in normal and breast cancer cells and contributes to their invasiveness
}

\author{
NAOKI NANASHIMA ${ }^{1}$, KAYO HORIE $^{1}$, TOSHIYUKI YAMADA $^{2}$, TAKESHI SHIMIZU ${ }^{2}$ and SHIGEKI TSUCHIDA ${ }^{2,3}$ \\ ${ }^{1}$ Department of Biomedical Sciences, Hirosaki University Graduate School of Health Sciences, Hirosaki 036-8564; \\ ${ }^{2}$ Department of Biochemistry and Genome Biology, Hirosaki University Graduate School of Medicine, Hirosaki 036-8562; \\ ${ }^{3}$ Department of Rehabilitation Sciences, Hirosaki University of Health and Welfare, \\ School of Health Sciences, Hirosaki 036-8102, Japan
}

Received September 30, 2016; Accepted November 5, 2016

DOI: $10.3892 /$ or.2017.5564

\begin{abstract}
Keratins are fibrous proteins. Hair keratins constitute hard structures such as the hair and nails, and cytokeratins have been used as markers of breast carcinoma. However, the expression and function of full-size hair keratin genes have not been previously demonstrated in breast cancer. We investigated the expression of the hair keratin, KRT81, and its function in human breast cancer and normal mammary epithelial cells. Western blotting showed full size 55-kDa KRT81 expression in the human breast cancer cell lines, MCF7, SKBR3 and MDA-MB-231, normal human mammary epithelial cells (HMEC), and non-neoplastic cells (MCF10A). Reverse transcription-polymerase chain reaction revealed that the full size KRT81, including its 5' region is expressed in breast cells. Immunohistochemical and immunofluorescence analyses showed that KRT81 was located in the cytoplasm. To investigate the function of KRT81, we knocked down KRT81 by siRNA in MCF10A cells. Microarray analysis revealed that the expression of genes related to invasion such as matrix metallopeptidase (MMP)9 was decreased. In KRT81-knockdown MDA-MB231 cells, zymography revealed a decrease in MMP9 activity, while scratch and invasion assays revealed that KRT81-knockdown decreased cell migration and invasion abilities. This is the first study showing that full size KRT81 is expressed in normal breast epithelial cells and breast cancer cells. Moreover, our results indicate that KRT81 contributes to the migration and invasion of breast cancer cells.
\end{abstract}

Correspondence to: Dr Naoki Nanashima, Department of Biomedical Sciences, Hirosaki University Graduate School of Health Sciences, 66-1 Hon-cho, Hirosaki 036-8564, Japan

E-mail:nnaoki@hirosaki-u.ac.jp

Abbreviations: KRT81, keratin 81; MMP, matrix metallopeptidase; qPCR, quantitative polymerase chain reaction; RT-PCR, reverse transcription-polymerase chain reaction; SDS-PAGE, sodium dodecyl sulfate-polyacrylamide gel electrophoresis

Key words: breast cancer, hair keratin, invasion, KRT81, MMP9

\section{Introduction}

Keratin is an intermediate filament expressed in epidermal cells of specific regions. The large keratin multigene family is comprised of cytokeratins, which are differentially expressed in various types of epithelia. Cytokeratins have been extensively studied as breast cancer markers $(1,2)$, and can be divided into the acidic type I and the basic-to-neutral type II cytokeratins. The intermediate filament network is formed through the obligatory association of equimolar amounts of type I and type II keratins (3). Hair keratins are expressed in hard-keratinized structures such as the hair and nails, and are believed to be structural proteins of the hair or nails that are not expressed in other organs such as the mammary gland. KRT81 is a type II hair keratin and one of the main hair proteins that is expressed in the hair cortex (4). However, it was reported that KRT81 is expressed in the human breast cancer cell line SKBR3 $(5,6)$ and in metastatic lymph nodes of breast carcinomas (7), but not in normal breast epithelial cells. Furthermore, the expressed KRT81 was a 5'-truncated isoform $(\Delta \mathrm{Hb} 1)$, and the full size protein was not expressed $(5,6)$. However, its function remains unclear.

The matrix metalloproteinase (MMP) family includes more than 20 isoforms that modulate the extracellular milieu by degrading extracellular matrix proteins. MMPs are secreted by fibroblasts and tumor cells and are involved in tumor invasion and metastasis $(8,9)$.

We previously reported that the hairless phenotype of the Hirosaki hairless rat (HHR) is due to the deletion of basic hair keratin genes, including KRT81 (10). HHR shows the involution by apoptosis of the mammary gland at an early stage of lactation (11), and is resistant to mammary tumors (12). A correlation between the incidence of breast cancer and an observed change in the X-ray diffraction pattern of hair from patients with breast cancer has been reported (13). Furthermore, X-ray diffraction of hair has the potential to provide a non-invasive test for the presence of breast cancer $(14,5)$.

These previous studies suggest that breast cancer may express hair keratin, and hair keratins may have some function in breast cells. The aim of the present study was to investigate the expression and the function of hair keratin KRT81 in normal breast and breast cancer cells. We investigated 
the expression of KRT81 using RT-PCR, western blotting and immunohistochemical analysis in human breast cancer cell lines, MCF7, SKBR3 and MDA-MB231, normal human mammary epithelial cells (HMECs) and non-neoplastic cells (MCF10A). To investigate the function of KRT81 in breast epithelial cells, we transfected MCF10A cells with siKRT81 and analyzed gene alterations using microarrays, Ingenuity ${ }^{\circledR}$ Pathway Analysis (IPA), and quantitative PCR (qPCR) to assess changes in gene expression. To investigate the effect of KRT81 on cell invasion, we performed zymography, scratch and invasion assays using the breast cancer cell line MDA-MB-231, which exhibits invasive properties (16). This is the first study on the expression of hair keratin KRT81 and its function in normal breast epithelial and cancer cells.

\section{Materials and methods}

Cell culture. HMECs were purchased from PromoCell GmbH (Heidelberg, Germany). The MCF10A human breast epithelial cell line, and MCF7, SKBR3 and MDA-MB-231 human breast cancer cell lines were obtained from the American Type Culture Collection (ATCC; Manassas, VA, USA). HMECs and MCF10A cells were routinely cultured using a Mammary epithelial cell growth medium kit at $37^{\circ} \mathrm{C}$ in $5 \% \mathrm{CO}_{2} . \mathrm{MCF} 7$, SKBR3 and MDA-MB-231 cells were routinely cultured in RPMI-1640 medium supplemented with $10 \%$ fetal bovine serum $(\mathrm{FBS})$ at $37^{\circ} \mathrm{C}$ in $5 \% \mathrm{CO}_{2}$.

siRNA transfection. The expression of rat KRT81 was blocked by transient transfection with KRT81 siRNA (Santa Cruz Biotechnology,Inc., Santa Cruz,CA, USA) using DharmaFECT Transfection Reagent (Thermo Scientific, Waltham, MA, USA). Approximately $2.5 \times 10^{5}$ MCF10A or MDA-MB-231 cells were incubated with siRNA for 24-48 h before being used for subsequent assays. For the negative control experiments, MCF10A or MDA-MB-231 cells were transfected with Silencer ${ }^{\circledR}$ Negative Control \#1 siRNA (Applied Biosystems, Foster City, CA, USA).

Western blot analysis. Western blotting was performed, according to the method described by Towbin et al (17). Proteins from HMECs, MCF10A, MCF7, SKBR3 and MDA-MB-231 cells were separated by SDS-polyacrylamide gel electrophoresis (PAGE) (18) on $7.5 \%(\mathrm{w} / \mathrm{v})$ polyacrylamide gels and electroblotted to Hybond nitrocellulose membranes (GE Healthcare, Piscataway, NJ, USA). Blots were probed with anti-KRT81 antibody-C-terminal (ab192689; 1:1,000; Abcam, Cambridge, MA, USA) or anti- $\beta$-actin antibody (dilution 1:1,000; Cell Signaling Technology, Danvers, MA, USA) followed by horseradish peroxidase-conjugated anti-guinea pig IgG (dilution 1:2,000; Abcam) or anti-rabbit IgG (dilution 1:2,000; Cell Signaling Technology). Signals were generated with an ECL kit (GE Healthcare) according to the manufacturer's protocol.

Reverse transcription-polymerase chain reaction ( $R T-P C R)$ and $q P C R$. Total RNA was extracted from the HMECs, MCF10A, MCF7, SKBR3 and MDA-MB-231 cells using the RNeasy Mini kit (Qiagen, Tokyo, Japan). cDNA was reverse-transcribed from total RNA (200 ng) using the
PrimeScript $^{\mathrm{TM}}$ RT Master Mix (Takara, Tokyo, Japan). PCR was performed with Takara LA Taq ${ }^{\circledR}$ with GC Buffer (Takara) using specific primer pairs. PCR amplification consisted of $30 \mathrm{sec}$ at $94^{\circ} \mathrm{C}, 30 \mathrm{sec}$ at $55-60^{\circ} \mathrm{C}$ and $30 \mathrm{sec}-2 \mathrm{~min}$ at $72^{\circ} \mathrm{C}$ for 40 cycles. Gene-specific primers were designed according to known human sequences using the Primer3Plus software. The primers used were as follows $\left(5^{\prime} \rightarrow 3^{\prime}\right)$ : KRT81 F-CCTGCGG ATCAGGATTTGGT (corresponding to exon 1) and R-AAGT GGGGGATCACACAGAG (corresponding to exon 9); GAPDH, F-AGAAGGCTGGGGCTCATTTG and R-AGGG GCCATCCACAGTCTTC. The RT-PCR products were subjected to electrophoresis on a $2 \%$ agarose gel and visualized with ethidium bromide. Levels of specific mRNAs were quantified by qPCR using SYBR-Green SuperMix (Bio-Rad Laboratories, Hercules, CA, USA). Transcript levels were normalized to that of GAPDH cDNA. The primers used were as follows $\left(5^{\prime} \rightarrow 3^{\prime}\right): K R T 81, \mathrm{~F}-\mathrm{AGGCTATGTGAAGGCATTGG}$ (corresponding to exon 8) and R-AAGTGGGGGATCACAC AGAG (corresponding to exon 9); GAPDH, F-AGAAGGCT GGGGCTCATTTG and R-AGGGGCCATCCACAGTCTTC; $M M P 9$, F-CACCTTCACTCGCGTGTAC and R-CATCTGC GTTTCCAAACCGAG. PCR specificity was ascertained by melting curve analysis. Relative gene expression was calculated according to the $2^{-\Delta \Delta \mathrm{Ct}}$ method.

Immunofluorescence staining. Cells were seeded onto a 4-well Slide \& Chamber (Watson, Japan) and incubated at $37^{\circ} \mathrm{C}$ for $24 \mathrm{~h}$, fixed immediately in $4 \%$ paraformaldehyde, and permeabilized in $0.1 \%$ Triton X-100 in phosphate-buffered saline (PBS) for $5 \mathrm{~min}$. The slides were then incubated with the anti-KRT81 antibody-C-terminal (ab192689; dilution 1:100) at $4^{\circ} \mathrm{C}$ overnight, followed by incubation with the secondary antibody, Alexa Fluor 647 anti-guinea pig IgG (ab150187; dilution 1:500) (both from Abcam) for $30 \mathrm{~min}$ at room temperature. Nuclear staining and mounting were performed with Vectashield Mounting Medium with 4',6-diamidino2-phenylindole (DAPI) (Vector Laboratories, Burlingame, CA, USA). Images were captured using a fluorescence microscope FSX100 (Olympus, Tokyo, Japan).

Histological analysis and immunohistochemistry. Breast cancer specimens, including normal areas, were obtained from patients at the time of surgery. The archival specimens were obtained from the Department of Pathology and Bioscience at Hirosaki University. The sections $(4-\mu \mathrm{m})$ were mounted onto silane-coated slides. Immunohistochemistry was automatically performed using the Ventana XT System Discovery ${ }^{\circledR}$ (Roche, Basel, Switzerland). Briefly, tissue sections were treated with protease I (Roche) at $37^{\circ} \mathrm{C}$ for $16 \mathrm{~min}$ for antigen retrieval. The following primary antibody was used: KRT81 polyclonal antibody (11342-1-AP; dilution 1:25; ProteinTech, Manchester, $\mathrm{UK}$ ), and sections were incubated at $37^{\circ} \mathrm{C}$ for $32 \mathrm{~min}$. The tissue sections were then incubated at $37^{\circ} \mathrm{C}$ for $20 \mathrm{~min}$ with a universal secondary antibody (Roche). The site of peroxidase binding was determined using DISCOVERY DABMap Detection kit (Roche). Sections were then counterstained with Hematoxylin II (Roche) for microscopic examination. As a negative control, non-immune $\gamma$-globulin was used instead of the antibody. The specimens were observed and photographed using a fluorescence microscope FSX100 (Olympus). The present study was 
A

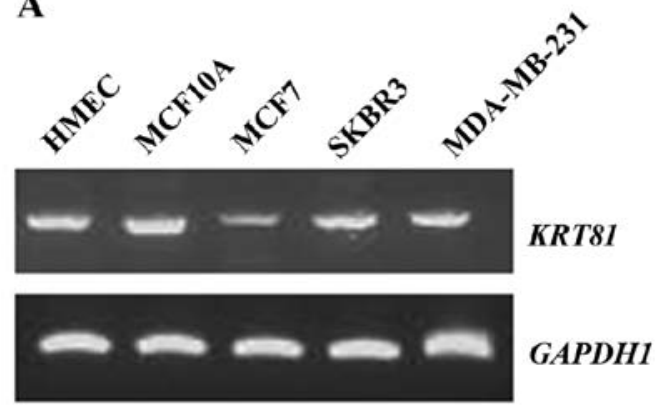

B

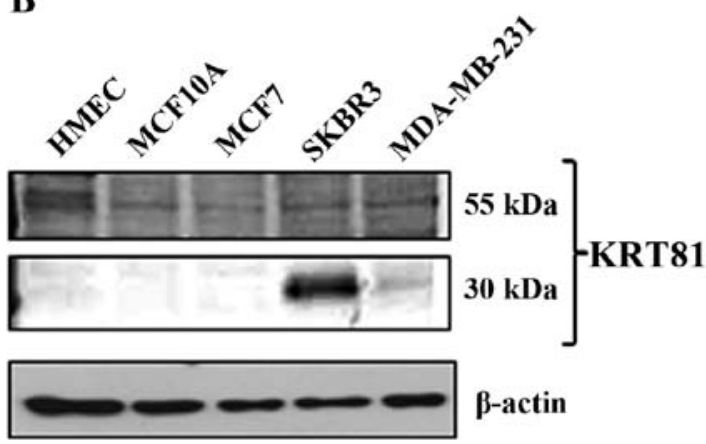

Figure 1. Expression of KRT81 mRNA and protein in normal breast epithelial and breast cancer cell lines. (A) RT-PCR was performed using the specific primers and mRNA isolated from each cell line. GAPDH mRNA was used as the control. (B) Western blotting to detect KRT81 or $\beta$-actin in each cell line. Proteins were resolved by SDS-PAGE and then blotted with an anti-KRT81 or anti- $\beta$-actin antibody.

approved by the Committee for Medical Ethics of Hirosaki University (Hirosaki, Japan). Informed consent was obtained from all patients prior to the beginning of the study.

Gene expression analysis by microarray. Total RNA was extracted from the siRNA-transfected or control MCF10A cells using the RNeasy Mini kit. One microgram of RNA was used to produce biotin-labeled complementary RNA (cRNA). The labeled and fragmented cRNA was subsequently hybridized to the SurePrint G3 Human Gene Expression microarray (8x60 K version 2; Agilent Technologies Inc., Santa Clara, CA, USA). Labeling, hybridization, image scanning and data analysis were performed at Bio Matrix Research Inc. (Chiba, Japan). The MCF10A microarray dataset is available at http://www.ncbi. nlm.nih.gov/geo under accession code GSE85236. Genes with 2-fold or greater upregulation following siRNA transfection were analyzed using the Qiagen Ingenuity ${ }^{\circledR}$ Pathway Analysis $\left(\right.$ IPA $\left.^{\circledR}\right)$ software (version 18030641). The z-score algorithm was utilized to decrease the possibility of false-positive results, where $z \geq 2$ indicated that transcript expression was significantly increased and $\mathrm{z} \leq-2$ indicated that the expression was significantly decreased.

Gelatin zymography. The MDA-MB-231 cells were grown to confluence in Dulbecco's modified Eagle's medium (DMEM) supplemented with $10 \%$ FBS. After $24 \mathrm{~h}$, the cells were transfected with siKRT81 or Silencer ${ }^{\circledR}$ Negative Control \#1 siRNA in serum-free medium. After $48 \mathrm{~h}$, the serum-free conditioned medium was harvested by centrifugation at $1,500 \mathrm{rpm}$ for 5 min. Gelatin zymography was performed as previously described $(19,20)$.

Scratch wound healing assay. The effects of KRT81 on cell migration were examined using the scratch wound healing assay with KRT81-silenced and control MDA-MB-231 cells. Briefly, $2 \times 10^{5}$ cells were seeded onto $60-\mathrm{mm}$ cell culture dishes. After cells reached $\sim 70 \%$ confluence as a monolayer, they were transfected with siKRT81. After $24 \mathrm{~h}$, the surface of the dishes was scratched linearly with a $200-\mu 1$ pipette tip. After $24 \mathrm{~h}$, images were captured using a fluorescence microscope CKX41 (Olympus). The cells that migrated were counted/field. Results were obtained from 3 independent experiments with 9 fields.
Invasion assay. The invasiveness of MDA-MB-231 cells treated or not with siKRT81 was assessed using Transwell chambers with $8-\mu \mathrm{m}$ pore size membrane (CytoSelect $^{\mathrm{TM}}$; Cell Biolabs, Inc., San Diego, CA, USA). Before the invasion assay, MDA-MB-231 cells were transfected with the siKRT81 and cultured for $24 \mathrm{~h}$ in another culture dish. In the upper compartment of the chamber, $\sim 1.5 \times 10^{5}$ cells (treated or not with siKRT81)/insert were added into the culture medium without serum, and $500 \mu \mathrm{l}$ of culture medium with $10 \%$ FBS were added to the lower well of the invasion chamber. The cells were incubated at $37^{\circ} \mathrm{C}$ in $5 \% \mathrm{CO}_{2}$ for $24 \mathrm{~h}$. Cells were then washed, fixed and stained with cell stain solution. Non-migrating cells were removed from the upper surface of the Transwell membrane with a cotton swab. Cells were counted with a fluorescence microscope FSX100. Results were obtained from 3 independent experiments with 9 fields.

Statistical analysis. Experiments were conducted at least 3 times in duplicate or triplicate. Results are presented as the mean \pm standard error of the mean (SEM). Statistical significance was determined using Student's t-test. $\mathrm{p}<0.01$ was considered statistically significant.

\section{Results}

KRT81 expression in normal breast epithelial and cancer cells. While northern blot analysis revealed that the human truncated form of KRT81 is expressed in breast cancer SKBR3 cells, but not in normal mammary glands $(5,6)$, no study has examined other breast cells by RT-PCR. Therefore, to determine the expression of KRT81 in breast cells, RT-PCR was performed using specific primers (forward primer located in exon 1 and reverse primer located in exon 9). Expression of KRT81, including the 5' region, resulting in a 1,674-bp product, was detected in all analyzed cells (Fig. 1A). To examine whether KRT81 protein is expressed in breast cancer cells, western blotting was performed with a KRT81 antibody. A 55-kDa protein was detected in all breast cell lines. Furthermore, a 30-kDa protein was detected in the SKBR3 and MDA-MB-231 cell lines (Fig. 1B). To examine the location of KRT81, we performed immunofluorescence staining using an anti-KRT81 antibody. The immunofluorescence staining revealed that KRT81 was expressed in the cytoplasm in all 


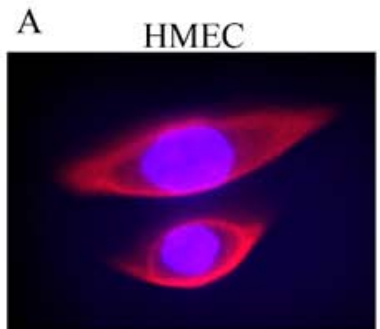

SKBR3

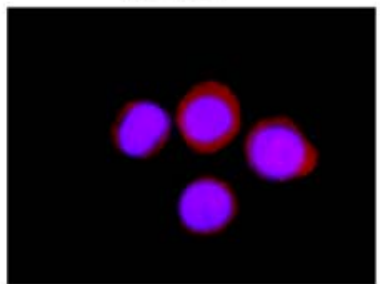

B

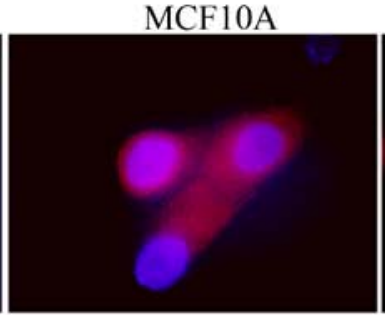

MDA-MB-231

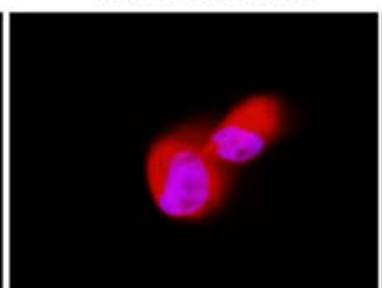

Breast cancer

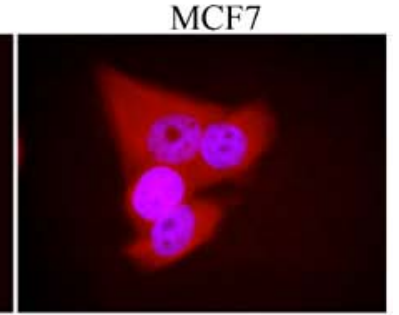

MCF10A

non-immune

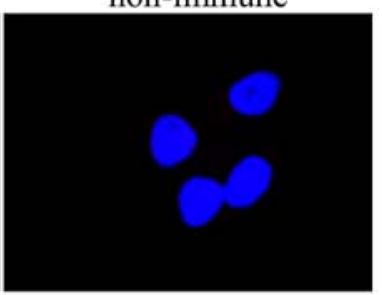

x800

\section{B}

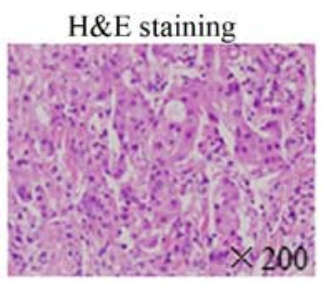

Non-immune
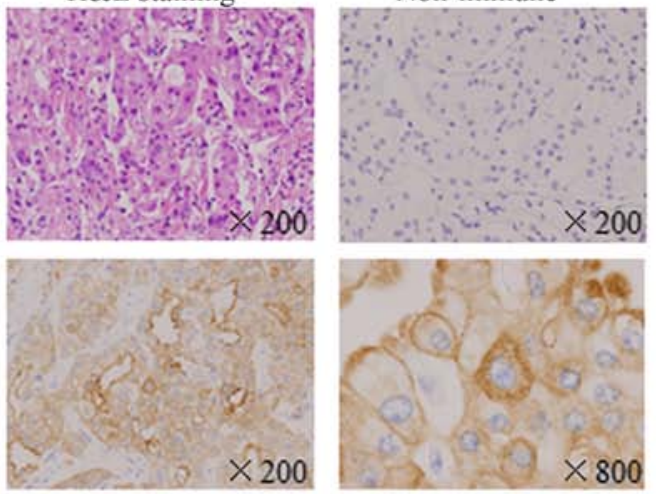

KRT 81

Normal mammary gland
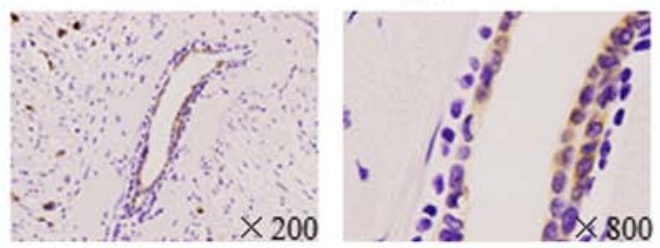

KRT81

Figure 2. Localization of KRT81 in normal breast epithelial and breast cancer cells. (A) Normal human mammary epithelial cells (HMECs) and MCF10A and breast cancer cell lines, MCF7, SKBR3 and MDA-MB-231, were stained with an anti-KRT81 antibody (Red Alexa Fluor 647). The cells were mounted with Vectashield Mounting Medium with DAPI to visualize the nuclei. As a negative control, non-immune $\gamma$-globulin was used instead of the antibody. Images are at a magnification of $\mathrm{x} 800$. (B) Breast tissue sections from patients with breast cancer were stained with H\&E or an anti-KRT81 antibody. Images are at a magnification of x200 (H\&E) and x200 or x800 (anti-KRT81 antibody or non-immune $\gamma$-globulin).
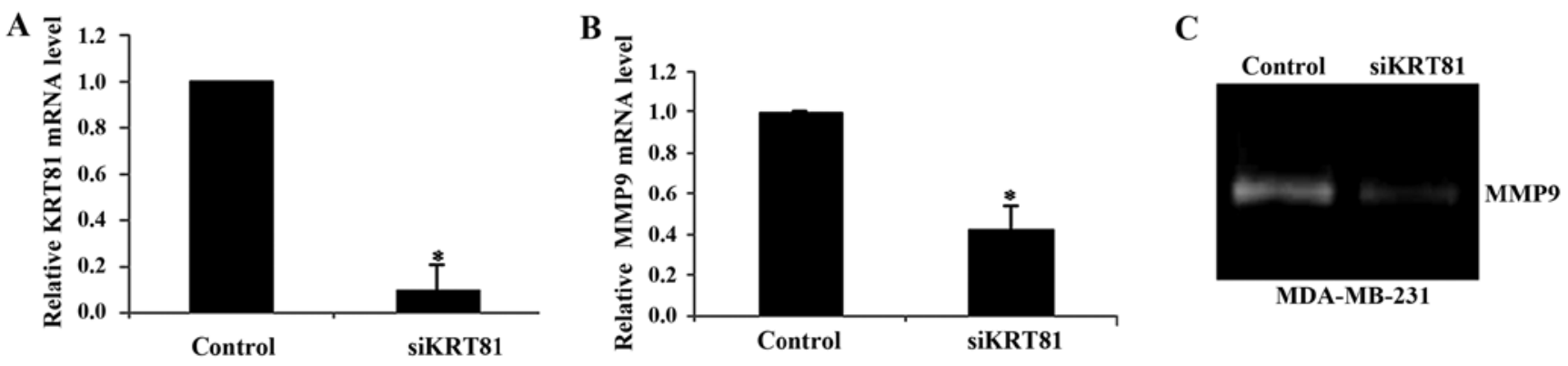

Figure 3. KRT81 knockdown results in a decrease in MMP9 expression in breast cancer MDA-MB-231 cells. MDA-MB-231 cells were transfected with KRT81 siRNA or a Silencer ${ }^{\circledR}$ Negative Control \#1 siRNA and cultured for 48 h. (A) KRT81 and (B) MMP9 mRNA expression was evaluated by qPCR; ${ }^{*}<0.01$ vs. the control. (B) Gelatin zymography of supernatants from the control and siKRT81-transfected MDA-MB-231 cells. 
A

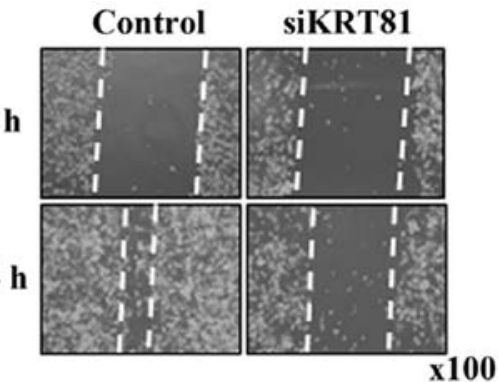

C

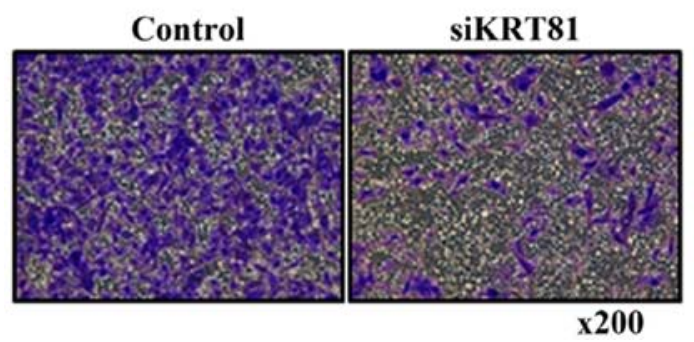

B

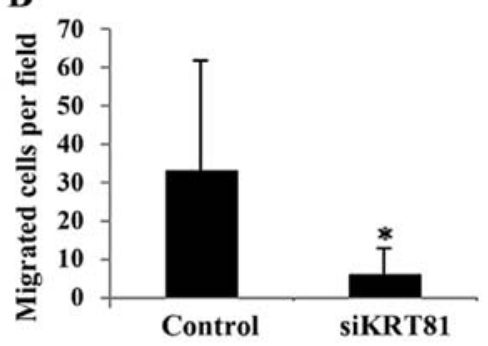

D

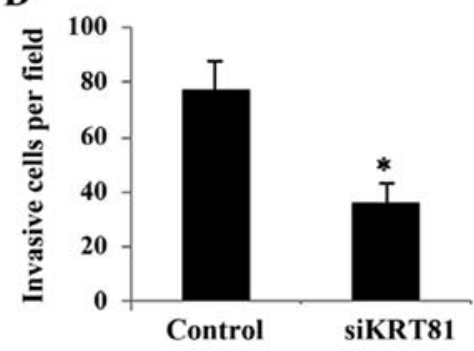

Figure 4. KRT81 knockdown inhibits the migration and invasion of MDA-MB-231 cells (A) MDA-MB-231 cells were transfected with KRT81 siRNA or a Negative Control \#1 siRNA and cultured. After 48 h, they were scratch-wounded and cultured for 24 h. (B) Cells that migrated/field; ${ }^{*}$ p $<0.01$ vs. the control. (C) MDA-MB-231 cells were transfected with KRT81 siRNA or a negative control \#1 siRNA and cultured. After 24 h, an invasion assay was performed as described in 'Materials and methods'. (D) Invasive cells/field; * $\mathrm{p}<0.01$ vs. the control.

breast cell lines (Fig. 2A). KRT81 expression in breast cancer tissue from patients was examined by immunohistochemistry with an anti-KRT81 antibody. KRT81 was expressed in the cytoplasm of ductal epithelial cells in breast cancer and normal areas (Fig. 2B). Staining with non-immune $\gamma$-globulin was negative. These results indicated that the full size and truncated form of KRT81 are expressed in human normal breast epithelial and cancer cells.

KRT81 knockdown downregulates the expression of invasion-related genes in MCF10A cells. To analyze the function of KRT81 in mammary epithelial cells, we transfected MCF10A cells with a KRT81 siRNA, and whole transcript profiling was performed by microarray analysis. IPA was performed to investigate the functional relationships between sets of genes with modified expression levels. Table I shows that invasion-related genes such as tumor necrosis factor (TNF), $M M P 9$ and Lipocalin 2 (LCN2) were downregulated in the siKRT81-transfected cells.

KRT81 knockdown decreases the migration and invasion abilities of MDA-MB-231 cells. Since MCF10A cells are noninvasive, we investigated the effect of KRT81 on cell invasion using the invasive breast cancer cell line MDA-MB-231. qPCR analysis revealed that KRT81 knockdown decreased KRT81 and $M M P 9$ expression at the mRNA level to 0.1 - and 0.5 -fold of that of the control cells, respectively ( $<<0.01$; Fig. 3A and B). Gelatin zymography revealed that MMP9 activity was decreased in the siKRT81-transfected cells (Fig. 3C). To investigate whether KRT81 affects migration and invasion, we performed scratch and invasion assays using MDA-MB-231 cells. siKRT81 knockdown decreased cell migration to 0.2 -fold $(\mathrm{p}<0.01$; Fig. 4A and B) and invasion to 0.5-fold (p<0.01; Fig. 4C and D). These results demonstrated that KRT81 contributes to breast cancer cell migration and invasion.
Table I. Invasion-related genes in breast cancer cell lines.

\begin{tabular}{llc}
\hline Gene symbol & \multicolumn{1}{c}{ Gene name } & Fold-change $^{\mathrm{a}}$ \\
\hline JUN & Jun proto-oncogene & 0.48 \\
ARF6 & ADP-ribosylation factor 6 & 0.46 \\
SP100 & SP100 nuclear antigen & 0.45 \\
HPSE & Heparanase & 0.45 \\
MMP7 & Matrix metallopeptidase 7 & 0.39 \\
MMP9 & Matrix metallopeptidase 9 & 0.45 \\
MMP10 & Matrix metallopeptidase 10 & 0.40 \\
MMP13 & Matrix metallopeptidase 13 & 0.14 \\
HIF1A & Hypoxia inducible factor 1 & 0.44 \\
TNF & Tumor necrosis factor & 0.42 \\
LCN2 & Lipocalin 2 & 0.38 \\
BMP2 & Bone morphogenetic protein 2 & 0.38 \\
PTGS2 & Prostaglandin-endoperoxide & 0.29 \\
& synthase 2 & \\
FAS & Fas (TNF receptor superfamily, & 0.24 \\
& member 6) & \\
TNFSF10 & Tumor necrosis factor & 0.09 \\
& superfamily, member 10 & \\
\hline
\end{tabular}

${ }^{a}$ Expression level in MCF10A cells transfected with KRT81 siRNA/negative control siRNA.

\section{Discussion}

Hair is produced by hair follicles. The embryonic mammary glands and hair follicles are both derived from the ventral ectoderm; mammary glands are skin appendages and their development depends on a number of common fundamental developmental pathways $(21,22)$. Therefore, we speculated 
Table II. EZH2-regulated genes in MCF10A cells.

\begin{tabular}{llc}
\hline Gene symbol & \multicolumn{1}{c}{ Gene name } & Fold-change \\
\hline TNF & Tumor necrosis factor & 0.42 \\
RARRES3 & Retinoic acid receptor responder 3 & 0.14 \\
PTGS2 & Prostaglandin-endoperoxide & 0.29 \\
& synthase 2 & \\
NCOA7 & Nuclear receptor co-activator 7 & 0.46 \\
LCN2 & Lipocalin 2 & 0.38 \\
KRT81 & Keratin 81 & 0.15 \\
IL6 & Interleukin 6 & 0.19 \\
IL24 & Interleukin 24 & 0.40 \\
CXCL10 & C-X-C motif chemokine & 0.05 \\
& ligand 10 & \\
C15orf48 & Chromosome 15 open & 0.20 \\
& reading frame 48 &
\end{tabular}

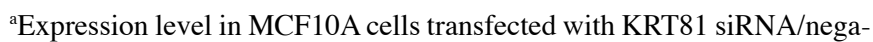
tive control siRNA. z-score of EZH2 was -2.61. EZH2, zeste 2 polycomb repressive complex 2 subunit.

that KRT81 expressed in breast cells may have some, yet, unknown functions. In the present study, we demonstrated the role of KRT81 in the migration and invasion of breast cancer cells.

A previous study revealed that $\Delta \mathrm{Hb} 1$, but not the full size KRT81, was expressed in the breast cancer cell line, SKBR3, but not in normal breast cells using northern blotting, and that $\Delta \mathrm{Hb} 1$ lacked the 270 amino terminal residues $(5,6)$. However, the present study revealed that the full size (exon 1-9) KRT81 mRNA and the 55-kDa KRT81 protein were expressed not only in breast cancer cells, but also in normal breast cells (Fig. 1A and B). In western blot analysis, the $55-\mathrm{kDa}$ KRT81 protein was detected in all breast cell lines, but the major band detected in the SKBR3 cells was $\Delta \mathrm{Hb} 1$ (30-kDa), suggesting that the amount of hair keratin proteins is low in breast cells. Furthermore, the amount of full size KRT81 was very low in typical breast cells, and the detection of $\Delta \mathrm{Hb} 1$ such as in SKBR3 cells appears rare. Immunohistochemistry revealed that KRT81 is located in the cytoplasm of breast cancer cells similar to cytokeratins, which suggests that KRT81 may have a function related to the cytoskeleton. However, recent studies proposed that cytokeratins not only function in the cytoskeleton, but also function as regulators of transcription factors and KRT17 may also be localized in the nucleus $(23,24)$. Furthermore, $\Delta \mathrm{Hb} 1$ was detected not only in breast cancer, but also in colon or nasopharyngeal carcinoma. It is thought that $\Delta \mathrm{Hb} 1$ may inhibit some of the functions of the keratin cytoskeleton or interfere with transcription regulation (25). Thus, KRT81 may have other functions in breast cells.

The siRNA-mediated KRT81-knockdown in MCF10A cells decreased the expression of invasion-related genes, including LCN2 and matrix metalloproteinases. LCN2 promotes mammary tumor formation and progression by upregulating matrix metalloproteinase expression (26). These alterations suggest inactivation of the NF- $\mathrm{B}$ pathway, since $L C N 2$ and
MMP9 expression is regulated by NF- $\mathrm{BB}(27,28)$. However, microarray and IPA analysis suggested that KRT81 knockdown did not alter the NF- $\kappa$ B pathway (data not shown), except for TNF expression, which was decreased (Table I). TNF is a known regulator of MMPs and LCN2 (29-31). In the present study, TNF, MMP9 and LCN2 expression was decreased in the siKRT81-treated MCF10A cells. Additionally, the expression of several TNF signaling-related genes, including Fas cell surface death receptor, tumor necrosis factor superfamily member 10 , and TNF receptor superfamily member 14 , was decreased (data not shown). While the function of hair keratins has not been reported, the functions of some keratins and TNF have been clarified. For example, keratin 8/18 and keratin 17 interact with the TNF receptor 1 (TNFR1)-associated death domain protein (TRADD), a death adaptor essential for TNFR1-dependent signaling. These keratins may attenuate TNF-induced apoptosis through association with TRADD. Furthermore, TNF regulates rat Krt23 (32) or human KRT15 (33). These studies suggest that KRT81 may also regulate TNF-dependent functions.

Furthermore, we performed an upstream regulator prediction analysis using IPA. The IPA analysis revealed that the predicted upstream regulator in siKRT81-treated MCF10A cells was the histone-lysine $\mathrm{N}$-methyltransferase enzyme, enhancer of zeste 2 polycomb repressive complex 2 subunit (EZH2), as EZH2 (z-score, -2.61) and the downstream genes of EZH2 were inhibited (Table II). Since EZH2 has been linked to cancer invasion or growth (34), recent studies have proposed that EZH2 may be useful as a therapeutic target $(35,36)$. Furthermore, it is known that EZH2 regulates the expression of KRT81, but its mechanism is unclear (37). Since KRT81 silencing downregulated EZH2-downstream genes such as LCN2 and MMP9, KRT81 may be involved in EZH2 activation.

In conclusion, this is the first study on KRT81 gene expression in normal and breast cancer cells, suggesting that KRT81 is involved in breast cancer migration and invasion. Collectively, the findings of the present study revealed that KRT81 is expressed in clinical specimens from patients with breast cancer. Indeed, it was reported that a KRT19 fragment in serum can be used as a marker of liver and breast cancer $(38,39)$, and KRT81 microRNA is associated with the risk and survival of patients with non-small cell lung cancer (40-42). Therefore, KRT81 may be used as a biomarker for patients with breast cancer once we clarify its biological significance.

\section{Acknowledgements}

The present study was supported in part by the JSPS KAKENHI (grant no. 20770096) and a Hirosaki University Institutional Research Grant for Young Scientists.

\section{References}

1. Charafe-Jauffret E, Ginestier C, Monville F, Finetti P, Adélaïde J, Cervera N, Fekairi S, Xerri L, Jacquemier J, Birnbaum D, et al: Gene expression profiling of breast cell lines identifies potential new basal markers. Oncogene 25: 2273-2284, 2006.

2. Cheang MC, Voduc D, Bajdik C, Leung S, McKinney S, Chia SK, Perou CM and Nielsen TO: Basal-like breast cancer defined by five biomarkers has superior prognostic value than triple-negative phenotype. Clin Cancer Res 14: 1368-1376, 2008. 
3. Langbein L, Rogers MA, Winter H, Praetzel S and Schweizer J: The catalog of human hair keratins. II. Expression of the six type II members in the hair follicle and the combined catalog of human type I and II keratins. J Biol Chem 276: 35123-35132, 2001.

4. Langbein L and Schweizer J: Keratins of the human hair follicle. Int Rev Cytol 243: 1-78, 2005.

5. Boulay A, Régnier CH, Anglard P, Stoll I, Tomasetto C and Rio MC: Transcription regulation and protein subcellular localization of the truncated basic hair keratin hHb1-DeltaN in human breast cancer cells. J Biol Chem 276: 22954-22964, 2001.

6. Régnier $\mathrm{CH}$, Boulay A, Asch PH, Wendling C, Chenard MP, Tomasetto $\mathrm{C}$ and Rio MC: Expression of a truncated form of hHb1 hair keratin in human breast carcinomas. Br J Cancer 78 1640-1644, 1998.

7. Tomasetto C, Régnier C, Moog-Lutz C, Mattei MG, Chenard MP, Lidereau R, Basset P and Rio MC: Identification of four novel human genes amplified and overexpressed in breast carcinoma and localized to the q11-q21.3 region of chromosome 17 Genomics 28: 367-376, 1995.

8. Figueira RC, Gomes LR, Neto JS, Silva FC, Silva ID and Sogayar MC: Correlation between MMPs and their inhibitors in breast cancer tumor tissue specimens and in cell lines with different metastatic potential. BMC Cancer 9: 20, 2009.

9. Ren F, Tang R, Zhang X, Madushi WM, Luo D, Dang Y, Li Z, Wei $\mathrm{K}$ and Chen G: Overexpression of MMP family members functions as prognostic biomarker for breast cancer patients: A systematic review and meta-analysis. PLoS One 10: e0135544, 2015.

10. Nanashima N, Akita M, Yamada T, Shimizu T, Nakano H, Fan Y and Tsuchida S: The hairless phenotype of the Hirosaki hairless rat is due to the deletion of an 80-kb genomic DNA containing five basic keratin genes. J Biol Chem 283: 16868-16875, 2008.

11. Nanashima N, Asano J, Hayakari M, Nakamura T, Nakano H, Yamada T, Shimizu T, Akita M, Fan Y and Tsuchida S: Nuclear localization of STAT5A modified with $O$-linked $\mathrm{N}$-acetylglucosamine and early involution in the mammary gland of Hirosaki hairless rat. J Biol Chem 280: 43010-43016, 2005.

12. Nanashima N, Yamada T, Shimizu T and Tsuchida S: Deletion of phospholipase $\mathrm{A}_{2}$ group IVc induces apoptosis in rat mammary tumour cells by the nuclear factor- $\kappa \mathrm{B} /$ lipocalin 2 pathway. Biochem J 469: 315-324, 2015.

13. James V, Kearsley J, Irving T, Amemiya Y and Cookson D Using hair to screen for breast cancer. Nature 398: 33-34, 1999

14. Corino GL and French PW: Diagnosis of breast cancer by X-ray diffraction of hair. Int J Cancer 122: 847-856, 2008

15. Corino GL, French PW, Lee M, Ajaj MM, Haklani J, Mistry DA Phan K and Yuile PG: Characterization of a test for invasive breast cancer using X-ray diffraction of hair-results of a clinical trial. Breast Cancer 3: 83-90, 2009.

16. Cailleau R, Young R, Olivé M and Reeves WJ Jr: Breast tumor cell lines from pleural effusions. J Natl Cancer Inst 53: 661-674, 1974.

17. Towbin H, Staehelin T and Gordon J: Electrophoretic transfer of proteins from polyacrylamide gels to nitrocellulose sheets: Procedure and some applications. Proc Natl Acad Sci USA 76: 4350-4354, 1979

18. Laemmli UK: Cleavage of structural proteins during the assembly of the head of bacteriophage T4. Nature 227: 680-685, 1970.

19. Miyazaki K, Hattori Y, Umenishi F, Yasumitsu $H$ and Umeda M: Purification and characterization of extracellular matrix-degrading metalloproteinase, matrin (pump-1), secreted from human rectal carcinoma cell line. Cancer Res 50: 7758-7764, 1990.

20. Umenishi F, Yasumitsu H, Ashida Y, Yamauti J, Umeda M and Miyazaki K: Purification and properties of extracellular matrixdegrading metallo-proteinase overproduced by Rous sarcoma virus-transformed rat liver cell line, and its identification as transin. J Biochem 108: 537-543, 1990.

21. Michno K, Boras-Granic K, Mill P, Hui CC and Hamel PA: Shh expression is required for embryonic hair follicle but not mammary gland development. Dev Biol 264: 153-165, 2003.

22. Mikkola ML and Millar SE: The mammary bud as a skin appendage: Unique and shared aspects of development. J Mammary Gland Biol Neoplasia 11: 187-203, 2006.
23. Escobar-Hoyos LF, Shah R, Roa-Peña L, Vanner EA, Najafian N, Banach A, Nielsen E, Al-Khalil R, Akalin A, Talmage D, et al: Keratin-17 promotes $\mathrm{p} 27^{\mathrm{KIP1}}$ nuclear export and degradation and offers potential prognostic utility. Cancer Res 75: 3650-3662, 2015.

24. Hobbs RP, Jacob JT and Coulombe PA: Keratins are going nuclear. Dev Cell 38: 227-233, 2016.

25. Nishikawa J, Kiss C, Imai S, Takada K, Okita K, Klein G and Szekely L: Upregulation of the truncated basic hair keratin 1(hHb1-DeltaN) in carcinoma cells by Epstein-Barr virus (EBV). Int J Cancer 107: 597-602, 2003.

26. Yang J, Bielenberg DR, Rodig SJ, Doiron R, Clifton MC, Kung AL, Strong RK, Zurakowski D and Moses MA: Lipocalin 2 promotes breast cancer progression. Proc Natl Acad Sci USA 106: 3913-3918, 2009.

27. Kang H, Lee M, Choi KC, Shin DM, Ko J and Jang SW: $N$-(4hydroxyphenyl)retinamide inhibits breast cancer cell invasion through suppressing NF-KB activation and inhibiting matrix metalloproteinase-9 expression. J Cell Biochem 113: 2845-2855, 2012.

28. Li SH, Hawthorne VS, Neal CL, Sanghera S, Xu J, Yang J, Guo H, Steeg PS and Yu D: Upregulation of neutrophil gelatinaseassociated lipocalin by ErbB2 through nuclear factor-kappaB activation. Cancer Res 69: 9163-9168, 2009.

29. Arena A, Stassi G, Iannello D, Gazzara D, Calapai M, Bisignano C, Bolignano D, Lacquaniti A and Buemi M: Both IL- $\beta$ and TNF- $\alpha$ regulate NGAL expression in polymorphonuclear granulocytes of chronic hemodialysis patients. Mediators Inflamm 2010: 613937, 2010.

30. Lee SJ, Park SS, Cho YH, Park K, Kim EJ, Jung KH, Kim SK, Kim WJ and Moon SK: Activation of matrix metalloproteinase-9 by TNF- $\alpha$ in human urinary bladder cancer HT1376 cells: The role of MAP kinase signaling pathways. Oncol Rep 19: 1007-1013, 2008

31. Moon SK, Cha BY and Kim CH: ERK1/2 mediates TNF-alphainduced matrix metalloproteinase- 9 expression in human vascular smooth muscle cells via the regulation of NF-kappaB and AP-1: Involvement of the ras dependent pathway. J Cell Physiol 198: 417-427, 2004

32. Zer C, Sachs G and Shin JM: Identification of genomic targets downstream of p38 mitogen-activated protein kinase pathway mediating tumor necrosis factor-alpha signaling. Physiol Genomics 31: 343-351, 2007.

33. Banno T, Gazel A and Blumenberg M: Effects of tumor necrosis factor-alpha (TNF alpha) in epidermal keratinocytes revealed using global transcriptional profiling. J Biol Chem 279: 32633-32642, 2004

34. Yoo KH and Hennighausen L: EZH2 methyltransferase and H3K27 methylation in breast cancer. Int J Biol Sci 8: 59-65, 2012.

35. Italiano A: Role of the EZH2 histone methyltransferase as a therapeutic target in cancer. Pharmacol Ther 165: 26-31, 2016.

36. Kim KH and Roberts CW: Targeting EZH2 in cancer. Nat Med 22: 128-134, 2016

37. Lee ST, Li Z, Wu Z, Aau M, Guan P, Karuturi RK, Liou YC and $\mathrm{Yu}$ Q: Context-specific regulation of $\mathrm{NF}-\kappa \mathrm{B}$ target gene expression by EZH2 in breast cancers. Mol Cell 43: 798-810, 2011.

38. Nakata B, Takashima T, Ogawa Y, Ishikawa T and Hirakawa K: Serum CYFRA 21-1 (cytokeratin-19 fragments) is a useful tumour marker for detecting disease relapse and assessing treatment efficacy in breast cancer. Br J Cancer 91: 873-878, 2004.

39. Uenishi T, Kubo S, Hirohashi K, Tanaka H, Shuto T, Yamamoto $T$ and Nishiguchi S: Cytokeratin-19 fragments in serum (CYFRA 21-1) as a marker in primary liver cancer. Br J Cancer 88: 1894-1899, 2003.

40. Campayo M, Navarro A, Viñolas N, Tejero R, Muñoz C, Diaz T, Marrades R, Cabanas ML, Gimferrer JM, Gascon P, et al: A dual role for KRT81: A miR-SNP associated with recurrence in nonsmall-cell lung cancer and a novel marker of squamous cell lung carcinoma. PLoS One 6: e22509, 2011.

41. Lee SY, Choi JE, Jeon HS, Hong MJ, Choi YY, Kang HG, Yoo SS, Lee EB, Jeong JY, Lee WK, et al: A genetic variation in microRNA target site of KRT81 gene is associated with survival in early-stage non-small-cell lung cancer. Ann Oncol 26: $1142-1148,2015$

42. Robles AI and Ryan BM: KRT81 miR-SNP rs 3660 is associated with risk and survival of NSCLC. Ann Oncol 27: 360-361, 2016. 